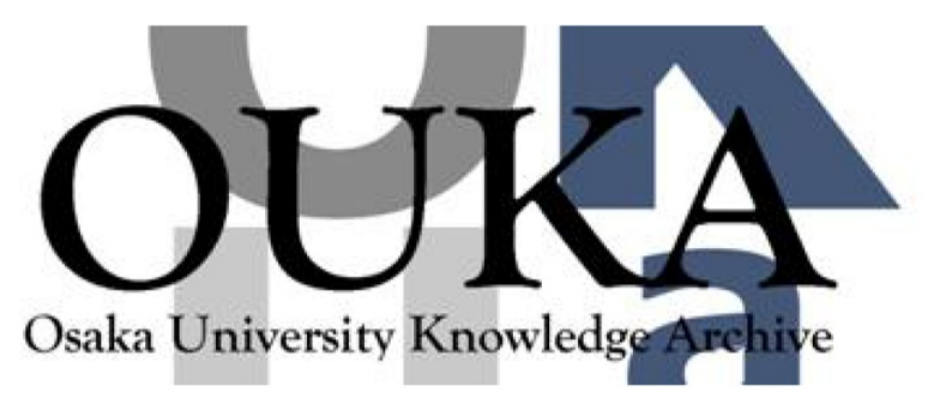

\begin{tabular}{|c|l|}
\hline Title & $\begin{array}{l}\text { Deposition of amorphous carbon nitride films on } \\
\text { flexible substrates by reactive sputtering for } \\
\text { applications in light-driven active devices }\end{array}$ \\
\hline Author(s) & $\begin{array}{l}\text { Aono, Masami; Harata, Tomo; Odawara, Taku et } \\
\text { al. }\end{array}$ \\
\hline Citation & $\begin{array}{l}\text { Japanese Journal of Applied Physics. 57(15) } \\
\text { p.01AC01 }\end{array}$ \\
\hline Issue Date & 2018 \\
\hline oaire:version & AM \\
\hline URL & https://hdl. handle. net/11094/78451 \\
\hline rights & 02018 The Japan Society of Applied Physics \\
\hline Note & \\
\hline
\end{tabular}

Osaka University Knowledge Archive : OUKA

https://ir. Library. osaka-u. ac. jp/

Osaka University 


\section{Deposition of amorphous carbon nitride films on flexible substrates by reactive sputtering for applications in light-driven active devices}

Masami Aono $^{1 *}$, Tomo Harata ${ }^{1}$, Taku Odawara ${ }^{1}$, Shinnosuke Asai ${ }^{1}$, Dai Orihara ${ }^{1}$, Masaya $\mathrm{Nogi}^{2}$

${ }^{1}$ Department of Materials Science and Engineering, National Defense Academy, Yokosuka, Kanagawa 239-8686, Japan

${ }^{2}$ The Institute of Scientific and Industrial Research, Osaka University, Ibaraki, Osaka, 5670047, Japan

*E-mail: aono@nda.ac.jp

Amorphous carbon nitride $\left(\mathrm{a}-\mathrm{CN}_{\mathrm{x}}\right)$ thin films deposited by reactive sputtering have great potential for driving source applications of light-driven active devices. We demonstrate, for the first time, the photoinduced deformation of a- $\mathrm{CN}_{\mathrm{x}}$ deposited on flexible substrates, namely, poly(ethylene naphthalate) (PEN) films and transparent cellulose nanopaper. a-CN $\mathrm{N}_{\mathrm{x}}$ films without delamination were obtained on both substrates. By decreasing the thickness of PEN films, the photoinduced deformation became extremely large. A light-driven pump was fabricated using a-CN $\mathrm{N}_{\mathrm{x}}$-coated PEN films, and then the pumping motion was observed up to $10 \mathrm{~Hz}$. When a He-Ne laser traced the surface of a- $\mathrm{CN}_{\mathrm{x}}$ films deposited on the nanopaper, the sample moved to the opposite side of the laser spot. The motion involved repeated expansions and contractions similar to the motion of caterpillars occurring owing to the temporary photoinduced deformation of a- $\mathrm{CN}_{\mathrm{x}}$ films. 


\section{Introduction}

Amorphous carbon nitride $\left(\mathrm{a}-\mathrm{CN}_{\mathrm{x}}\right)$ thin films possess many properties such as high hardness, ${ }^{1,2)}$ low friction coefficient, ${ }^{1,2)}$ pressure sensitivity, ${ }^{3)}$ photocatalytic effects, ${ }^{4-6)}$ and variable bandgaps. ${ }^{7}$ Recently, deformation under visible-light irradiation has been revealed in a-CN $\mathrm{CN}_{\mathrm{X}}$ thin films prepared by reactive sputtering using nitrogen radicals. ${ }^{8,9)}$

We have reported that this photoinduced deformation has the following characteristics: (1) this phenomenon can be observed in the whole range of visible light, (2) the deformation occurs owing to the contraction of the film surface, (3) the amount of deformation is small under photothermal effects, and (4) it involves repeated motions corresponding to the switching on/off of light. ${ }^{8-10)}$ The amount of deformation is maximum in the blue region at around $460 \mathrm{~nm}$ in wavelength. ${ }^{10)}$ Photothermal effects are most likely the causes of the photoinduced deformation. However, the increase in the temperature of the film surface was less than $\left.1 \mathrm{~K}^{9}{ }^{9}\right)$

The development of a technique to directly convert the energy of photons to kinetic energy as in photoinduced deformation is expected to lead to the realization of light-driven devices owing to less electrical power sources and signal lines, and indirect control and miniaturization of devices. Materials must be developed and several technical challenges must be overcome to realize device applications, such as increasing energy conversion efficiency and kinetic power and obtaining rapid responses. Response time, which is one of the limitations, and the amount of photoinduced deformation are determined by the mechanical properties of the substrate materials of bilayer structured specimens including a$\mathrm{CN}_{\mathrm{x}}$ films. On an a-CN $\mathrm{CN}_{\mathrm{X}} / \mathrm{SiO}_{2}$ bilayer specimen with dimensions of $2 \times 30 \times 0.05 \mathrm{~mm}^{3}$, the amount of photoinduced deformation is less than $400 \mu \mathrm{m}$ and the response takes a few seconds to complete. ${ }^{11)}$

To increase the amount of photoinduced deformation, we prepared self-standing films and films deposited on flexible substrates. Substrate materials should be not only flexible but also lightweight and have thermal stability, resistance to plasma radiation, and highvacuum tolerance. Thus, we chose two transparent flexible sheets as substrates, poly(ethylene naphthalate) (PEN) film and cellulose nanopaper.

A PEN film has excellent plasma resistance, high transparency $(>85 \%)$, relatively high thermal stability (glass transition temperature, $\sim 428 \mathrm{~K}$ ), and the lowest coefficient of thermal expansion $\left.(13 \mathrm{ppm} / \mathrm{K}){ }^{12}{ }^{13}\right) \mathrm{PEN}$ films have been used as substrates of transparent conducting thin films deposited by sputtering. ${ }^{14-16)}$

Conventional cellulose paper is lightweight and has flexible workability, but its 
transparency to visible light is low. Transparent cellulose nanopaper, which contains only nanosized cellulose fibers, has a high optical transparency and a smooth surface, which make this nanopapers suitable as a substrate. ${ }^{17}{ }^{18)}$ This nanopaper exhibits a low coefficient of thermal expansion similarly to glass, and higher thermal durability and dielectric constant than most plastics because of the excellent mechanical properties of the cellulose nanofibers. ${ }^{17-20)}$ By utilizing these advantages, flexible devices have been fabricated using cellulose nanopaper, such as organic solar cells, transistors, antennas, and memories. ${ }^{21,22)}$ Therefore, transparent cellulose nanopaper is a promising substrate for future light-driven active devices.

\section{Experimental methods}

a- $\mathrm{CN}_{\mathrm{x}}$ films were prepared using a reactive radio-frequency magnetron sputtering system. The sputtering target was a graphite disc approximately $5 \mathrm{~cm}$ in diameter. The sputtering gas was $\mathrm{N}_{2}$ with $99.9995 \%$ purity. All the films used in this study were deposited at room temperature. The RF power was $85 \mathrm{~W}$ at $13.56 \mathrm{MHz}$. The $\mathrm{N}_{2}$ gas pressure during the deposition was kept constant at about $16 \mathrm{~Pa}$.

To obtain a self-standing film, a- $\mathrm{CN}_{\mathrm{x}}$ was deposited on a $\mathrm{Si}$ substrate. The a- $\mathrm{CN}_{\mathrm{x}}$ on the substrate was put into a water pool. Then, the film that peeled off from the substrate was skimmed.

The substrate materials were PEN films (Teijin DuPont Films Japan Teonex®) and transparent cellulose nanopaper. We cut PEN films to be $0.5 \mathrm{~cm}$ in width and $2.0 \mathrm{~cm}$ in lenght. The PEN film thicknesses were 12, 25, 50, and $100 \mu \mathrm{m}$. These four PEN films with different thicknesses were deposited all together.

Cellulose nanofibers $15 \mathrm{~nm}$ in width were mechanically nanofibrillated from alkalitreated holocellulose pulp of Japanese cedar using a high-pressure water jet system (Sugino Machine Star Burst HJP-25005E). ${ }^{18,23)}$ Optically transparent nanofiber paper was fabricated by drying the nanofiber/water dispersion. ${ }^{18,23)}$ The sheets of cellulose nanopaper were approximately $5 \mathrm{~mm}$ in width, $7 \mathrm{~mm}$ in length, and $20 \mu \mathrm{m}$ in thickness. Both the PEN films and nanopaper sheets were cleaned with ethanol.

Nitrogen concentration ( $\mathrm{x}=\mathrm{N} / \mathrm{C}$ ) was determined by X-ray photoelectron spectroscopy (XPS; Kratos Analytical AXIS Supra) using monochromatic Al Ka (1486.6 eV) radiation. The N/C ratio was estimated from the area intensities of $\mathrm{N} 1 \mathrm{~s}$ and $\mathrm{C} 1 \mathrm{~s}$ core-level spectra. 
Surface morphology was observed under an optical microscope (Keyence VH-5000) and by scanning electron microscopy (SEM; JEOL JCM-6000). SEM had an acceleration voltage of $15 \mathrm{kV}$ and a working distance of $20 \mathrm{~mm}$.

In the photoinduced deformation measurement of a- $\mathrm{CN}_{\mathrm{x}}$ deposited on PEN film, a Xe lamp of $150 \mathrm{~W}$ was used to irradiate the a- $\mathrm{CN}_{\mathrm{x}}$ film surface through an IR cut-off filter. In addition, a He-Ne laser with $633 \mathrm{~nm}$ wavelength and a semiconductor laser with $356 \mathrm{~nm}$ wavelength were used as excitation light.

\section{Results and discussion}

\subsection{Photomechanical responses of self-standing films}

Figure 1 (see also Movie 1 in the online supplementary data at http:// ) shows the photomechanical responses of self-standing films. Macroscopic responses were observed. On the self-standing films, however, amplitude decay was obtained with increasing frequency of switching on and off the incident light. Self-standing films are fragile owing to their low density and weak bonds. ${ }^{24)}$ Thus, a substrate is necessary for long-term stable performance of light-driven devices fabricated using a- $\mathrm{CN}_{\mathrm{x}}$ films. The choice of appropriate substrate materials that maintain the photoinduced deformation is quite important for device applications of a-CN $\mathrm{CN}_{\mathrm{x}}$ films.

\subsection{Deposition on PEN films}

Figure 2 shows optical microscopy images of the surface of a PEN film before and after deposition. a- $\mathrm{CN}_{\mathrm{x}}$ films were deposited uniformly on PEN films without delamination. The nitrogen concentration $\mathrm{x}$ of a- $\mathrm{CN}_{\mathrm{x}}$ films was estimated from $\mathrm{C} 1 \mathrm{~s}$ and $\mathrm{N} 1 \mathrm{~s}$ XPS spectra to be $0.6 \pm 0.1$, as shown in Fig. 3 .

Owing to the residual stress in a-CN $\mathrm{CN}_{\mathrm{x}}$ films, the a-CN $\mathrm{CN}_{\mathrm{x}}$-coated PEN films curved naturally, as shown on the left side of Fig. 4. This intrinsic stress evolution in a- $\mathrm{CN}_{\mathrm{x}}$ films has been attributed to the structural transformation induced by nitrogen incorporation and by C-C distortions. ${ }^{25,26)}$ The external sides were a- $\mathrm{CN}_{\mathrm{x}}$ films. Regarding amorphous carbonrelated films, including diamond-like carbon (DLC) and $\mathrm{a}-\mathrm{CN}_{\mathrm{x}}$, their delamination from substrates owing to their high residual stress is basically one of the major issues. Thus, an interlayer such as a metal is sometimes required for depositing carbon-related films on $\mathrm{Si}$ and $\mathrm{SiO}_{2}$ substrates. ${ }^{27-29)}$ Substrates such as PEN films with flexibility can relax the high residual stress of $\mathrm{a}-\mathrm{CN}_{\mathrm{x}}$ without delamination. 
Upon visible light irradiation, the a- $\mathrm{CN}_{\mathrm{x}}$-coated PEN film was flat, as shown in Fig. 4. This condition can be observed by the naked eye and suggests that the photoinduced deformation of a-CN $\mathrm{CN}_{\mathrm{x}}$ is due to photoinduced stress. The curvature of the samples decreased with increasing thickness of PEN films, as shown in Fig. 5.

Residual stress in the dark, $\sigma_{\mathrm{d}}$, is defined as ${ }^{30)}$

$$
\sigma_{d}=-\frac{E_{s}}{1-v_{s}} \frac{\kappa_{d} d_{s}^{2}}{6 d_{f}}
$$

where $E$ is Young's modulus and $v$ is Poisson's ratio. The subscripts $s$ and $f$ indicate the substrate and film, respectively. $\kappa$ is the curvature, with positive values indicating convexity on the film surface and negative values indicating concavity. The subscript $d$ indicates the values obtained in the dark. The stress under illumination, $\sigma_{\mathrm{p}}$ is also obtained from the equation. The thickness of a-CN $\mathrm{CN}_{\mathrm{x}}$ films, $d_{f}$, is kept constant at about $1.2 \mu \mathrm{m}$ throughout the deposition time of $60 \mathrm{~min}$. Thus, the average photoinduced stress $\Delta \sigma$ is given by

$$
\Delta \sigma=\sigma_{d}-\sigma_{p}=-\frac{E_{s}}{1-v_{s}} \frac{d_{s}^{2}}{6 d_{f}}\left(\kappa_{d}-\kappa_{p}\right)
$$

$\Delta \sigma$ of a- $\mathrm{CN}_{\mathrm{x}}$ deposited at RT was about $9.3 \mathrm{MPa}$.

Photoinduced deformation of a- $\mathrm{CN}_{\mathrm{x}}$ depends on fundamental properties, such as N/C ratio, graphitic cluster size, and bonding structures. From a previous work ${ }^{31)}$, the features of a- $\mathrm{CN}_{\mathrm{x}}$ films with a large amount of deformation are as follows: $\mathrm{N} / \mathrm{C}$ of approximately 0.5 , relatively small graphite clusters, and an existence of termination structures, e.g., $-\mathrm{C} \equiv \mathrm{N}$. Recently, the largest amount of photoinduced deformation was obtained for a- $\mathrm{CN}_{\mathrm{x}}$ deposited at $573 \mathrm{~K} .{ }^{9)}$ When using PEN films as the substrate, a large amount of photoinduced deformation observed by the naked eye is also obtained in a- $\mathrm{CN}_{\mathrm{x}}$ deposited at room temperature.

A light-driven pump was fabricated using a- $\mathrm{CN}_{\mathrm{x}}$-coated PEN films because a large photoinduced motion was obtained on these samples, as mentioned above. The body of the pump, except the diaphragm, was made of quartz glass. The diaphragm was made of a- $\mathrm{CN}_{\mathrm{x}^{-}}$ coated PEN film with a thickness of $12 \mu \mathrm{m}$. The hole was $5 \mathrm{~mm}$ in diameter and $50 \mu \mathrm{m}$ in depth.

A semiconductor laser was used for irradiating light at $375 \mathrm{~nm}$ wavelength. Pumping motion was observed in both diaphragms. Figure 6(a) shows the amplitude of the a-CN $\mathrm{N}_{\mathrm{x}} / \mathrm{PEN}$ diaphragm with a chopping frequency of $0.1 \mathrm{~Hz}$. The amplitude of the a-CN $\mathrm{N}_{x} / \mathrm{PEN}$ diaphragm is 5 times larger than that of the a- $\mathrm{CN}_{\mathrm{x}} / \mathrm{SiO}_{2}$ diaphragm. ${ }^{32)}$ The pumping motion in this study was observed up to $10 \mathrm{~Hz}$, as shown in Fig. 6(b). 


\subsection{Deposition on transparent cellulose nanopaper}

Figure 7 shows optical microscopy images of transparent cellulose nanopaper and a- $\mathrm{CN}_{\mathrm{x}}$ film deposited on the nanopaper. The surface morphology of a- $\mathrm{CN}_{\mathrm{x}}$ films reflected that of cellulose nanopaper. A cross sectional SEM image in the inset of Fig. 7(b) shows that the a$\mathrm{CN}_{\mathrm{x}}$ film smoothly covered the surface of transparent cellulose nanopaper.

We cut the paper into a trapezoid after the deposition. The sample size was about 5 $\mathrm{mm}$ in height, $1.25 \mathrm{~mm}$ in length at the top, and $3.3 \mathrm{~mm}$ in length at the bottom. The bottom side $0.5 \mathrm{~mm}$ from the edge was uncovered by a- $\mathrm{CN}_{\mathrm{x}}$ films. The a- $\mathrm{CN}_{\mathrm{x}}$ film did not delaminate, even when the film was cut, because the adhesion of a- $\mathrm{CN}_{\mathrm{x}}$ films on cellulose nanopaper is high owing to the rough surface of the nanopaper. Figure 8 (see Movie 2 in the online supplementary data at http:// ) shows the self-active motion of the sample through contraction and expansion of the a- $\mathrm{CN}_{\mathrm{x}}$ deposited on the nanopaper. A sequence of frames indicates how such a film can be moved by irradiation with the red light of the He-Ne laser $(\lambda=633 \mathrm{~nm})$. The first frame in Fig. 8 shows the film before light irradiation. The samples curled up after deposition owing to the residual stress of $\mathrm{a}-\mathrm{CN}_{\mathrm{x}}$, as mentioned above. The radius of curvature of a- $\mathrm{CN}_{\mathrm{x}}$ film on cellulose nanopaper in the dark was smaller than that of the PEN film with a thickness of $12 \mu \mathrm{m}$. This is due to the elastic modulus of cellulose nanopaper (ca. $138 \mathrm{GPa}^{33)}$ ) being higher than that of PEN film (ca. $3.3 \mathrm{GPa}^{34)}$ ). The second frame shows how part of the sample became flat during illumination. The partially flat state remained during exposure to light. When the light was turned off, the curvature recovered. When a laser spot was traced on the sample surface following the arrow in the second frame, the sample moved to the opposite side of the arrow. Then, a bare surface of the nanopaper prevented the sample from retreating because the friction coefficient of the paper is higher than that of a-CN $\mathrm{CN}_{\mathrm{x}}$ films. ${ }^{35)}$ Thus, the sample moves to one direction. This self-active motion was based on the partial expansion and contraction of a- $\mathrm{CN}_{\mathrm{x}}$ films.

\section{Conclusions}

a- $\mathrm{CN}_{\mathrm{x}}$ thin films were prepared by reactive radio-frequency magnetron sputtering on the flexible substrates: PEN film and transparent cellulose nanopaper. After the deposition, a$\mathrm{CN}_{\mathrm{x}}$ films without delamination and cracks were obtained on both substrates. In addition, the samples were bent owing to the residual stress of a-CN $\mathrm{N}_{\mathrm{x}}$ films in accordance with the mechanical properties of substrates.

By decreasing the thickness of PEN films, the photoinduced deformation became 
extremely large. A light-driven pump was fabricatied using a- $\mathrm{CN}_{\mathrm{x}}$-coated PEN films, and then the pumping motion was observed up to $10 \mathrm{~Hz}$. When the He-Ne laser traced the surface of a- $\mathrm{CN}_{\mathrm{x}}$ films deposited on the nanopaper, the sample moved to the opposite side of the laser spot. This motion was due to the partial expansion and contraction of the sample, similar to the motion of caterpillars. These photomechanical responses as a result of a temporary photoinduced deformation under visible light is useful in the development of microscale and nanoscale motors.

\section{Acknowledgments}

This work was supported by JSPS KAKENHI Grant Number 26790054. PEN films were provided by Teijin DuPont Films Japan Ltd. 


\section{References}

1) H. Inoue, S. Muto, S. Arai, H. Wasada, and N. Umehara, Surf. Coatings Technol. 313, 31 (2017).

2) K. D. Bakoglidis, H. Glenat, G. Greczynski, S. Schmidt, S. Grillo, L. Hultman, and E. Broitman, Wear 370-371, 1 (2017).

3) N. Tamura, M. Aono, H. Abe, N. Kitazawa, and Y. Watanabe, Jpn. J. Appl. Phys. 54, 041401 (2015).

4) H. Dai, X. Gao, E. Liu, Y. Yang, W. Hou, L. Kang, J. Fan, and X. Hu, Diamond Relat. Mater. 38, 109 (2013).

5) J. Yu, S. Wang, J. Low, and W. Xiao, Phys. Chem. Chem. Phys. 15, 16883 (2013).

6) L. Z. Liu, X. L. Wu, X. X. Liu, and P. K. Chu, Appl. Phys. Lett. 106, 132406 (2015).

7) M. Aono, T. Goto, N. Tamura, N. Kitazawa, and Y. Watanabe, Diamond Relat. Mater. 20, $1208(2011)$.

8) M. Aono, T. Harata, N. Kitazawa, and Y. Watanabe, Diamond Relat. Mater. 41, 20 (2014).

9) T. Harata, M. Aono, N. Kitazawa, and Y. Watanabe, Appl. Phys. Lett. 105, 051905 (2014).

10) T. Harata, M. Aono, N. Tamura, N. Kitazawa, and Y. Watanabe J. Phys.: Conf. Ser. 619, 012007 (2015).

11) T. Harata, M. Aono, H. Kishimura, N. Kitazawa, and Y. Watanabe, e-J. Surf. Sci. Nanotechnol. 13, 352 (2015).

12) E. L. Bedia, S. Murakami, T. Kitade, and S. Kohjuya, Polymer 42, 7299 (2001).

13) www.teijindupontfilms.jp/english/product/pen_teo.html

14) J. -M. Kim, P. Thiyagarajan, and S. -W. Rhee, Thin Solid Films 518, 5960 (2010).

15) H. -S. Chin, L. -S. Chao, and C. -C. Wu, Mater. Res. Bull. 79, 90 (2016).

16) H. Shen, H. Zhang, L. Lu, F. Jiang, and C. Yang, Prog. Nat. Sci.: Mater. Int. 20, 44 (2010).

17) M. Nogi, S. Iwamoto, A. N. Nakagaito, and H. Yano, Adv. Mater. 21, 1595 (2009).

18) M. Nogi, C. Kim, T. Sugahara, T. Inui, T. Takahashi, and K. Suganuma, Appl. Phys. Lett. 102, 181911 (2013).

19) T. Saito, R. Kuramae, J. Wohlert, L. A. Berglund, and A. Isogai, Biomacromolecules 14, 248 (2013).

20) T. Inui, H. Koga, M. Nogi, and K. Suganuma, Adv. Mater. 27, 1112 (2015).

21) H. Yagyu, S. Ifuku, and M. Nogi, Flexible Printed Electron. 2, 014003 (2017).

22) M. -C. Hsieh, C. Kimu, M. Nogi, and K. Suganuma, Nanoscale 5, 9289 (2013).

23) H. Yagyu, T. Saito, A. Isogai, H. Kota, and M. Nogi, ACS Appl. Mater. Interfaces 7, 22012 (2015). 
24) M. Aono, S. Kikuchi, N. Tamura, N. Kitazawa, Y. Watanabe, and S. Nitta, Physica Status Solidi C 7, 797 (2000).

25) M. Aono, S. Nitta, T. Katsuno, and T. Iuchi, J. Vac. Sci. Technol. B 18, 1773 (2000).

26) M. Therasse and M. Benlahsen, Solid State Commun. 129, 139 (2004).

27) J. Li, W. T. Zhang, Z. Jin, X. Lu, G. Gu, X. Mei, and C. Dong, Appl. Surf. Sci. 191, 273 (2002).

28) D. G. Liu, W.Q. Bai, Y. J. Pan, and J. P. Tu, Vacuum 125, 36 (2016).

29) D. -J. Jan and C. -F. Ai, Mater. Chem. Phys. 72, 158 (2001).

30) D. L. Smith, Thin-Film Deposition (McGraw-Hill, New York, 1995) p. 188.

31) T. Harata, M. Aono, N. Kitazawa, and Y. Watanabe, Jpn. J. Appl. Phys. 55, 01AA01 (2016).

32) M. Aono and T. Harata, New Diamond 124, 32 (2017) [in Japanese].

33) T. Nishino, K. Takano, and K. Nakamae, J. Polym. Sci., Part B 33, 1647 (1995).

34) K. A. Sierros, D. A. Banerjee, N. J. Morris, D. R. Cairns, I. Kortidis, and G. Kiriakidis, Thin Solid Films 519, 325 (2010).

35) P. Wang, T. Takeno, K. Adachi, H. Miki, and T. Takagi, Appl. Surf. Sci. 258, 6576 (2012). 


\section{Figure Captions}

Fig. 1. (Color online) Folding motion of self-standing a-CN $\mathrm{N}_{\mathrm{x}}$ film. The film is illuminated with white light from the left side.

Fig. 2. (Color online) Optical microscopy images. (a) Surface image of PEN film and (b) a-CN $\mathrm{CN}_{\mathrm{x}}$ deposited on PEN film (12 $\mu \mathrm{m}$ thickness).

Fig. 3. $\mathrm{C} 1 \mathrm{~s}$ and $\mathrm{N} 1 \mathrm{~s}$ photoelectron peaks of the a-CN $\mathrm{CN}_{\mathrm{x}}$ film grown at room temperature.

Fig. 4. (Color online) Photoinduced deformation of a-CN $\mathrm{CN}_{x}$ on PEN films. The sample is held in air from the top edge, and illuminated with white light normal to its surface. The light is incident from the left side.

Fig. 5. Curvature of a-CN $\mathrm{CN}_{\mathrm{x}}$ films deposited on PEN films in the dark and under light as a function of the thickness of PEN films.

Fig. 6. Light-driven pump using a-CN $\mathrm{CN}_{\mathrm{x}}$ deposited on PEN films (12 mm thickness). (a) Light response of the pump with a chopping frequency of $0.5 \mathrm{~Hz}$. (b) Amplitude of the diaphragms as a function of chopping frequency.

Fig. 7. (Color online) Optical microscopy images. Surface images of (a) transparent cellulose nanopaper and (b) a- $\mathrm{CN}_{\mathrm{x}}$ film deposited on the paper. A cross-sectional SEM image of a$\mathrm{CN}_{\mathrm{x}}$ film deposited on the paper is shown in the inset.

Fig. 8. (Color online) Wobble motion of a-CN $\mathrm{CN}_{\mathrm{x}}$-coated transparent cellulose nanopaper following irradiation with He-Ne laser. The light is incident from above. 


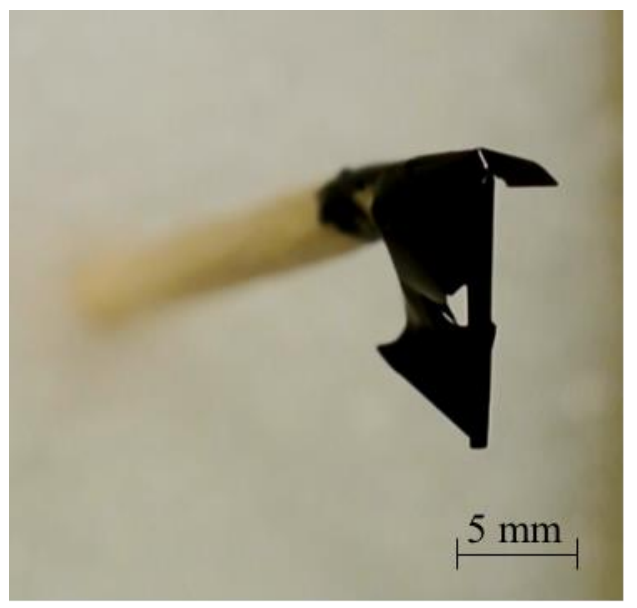

(a)

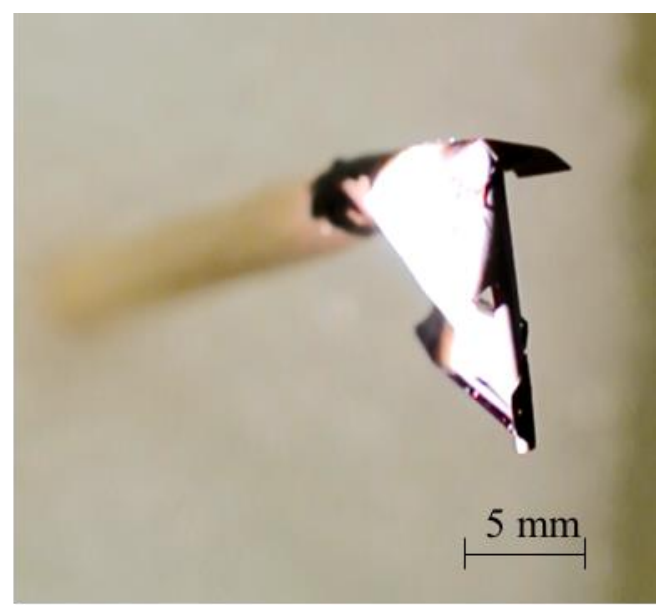

(b)

Fig. 1. (Color Online) 


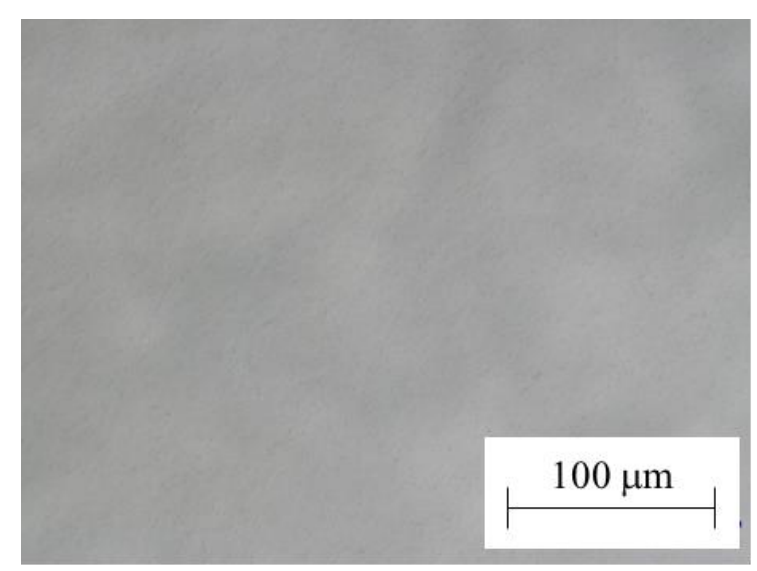

(a)

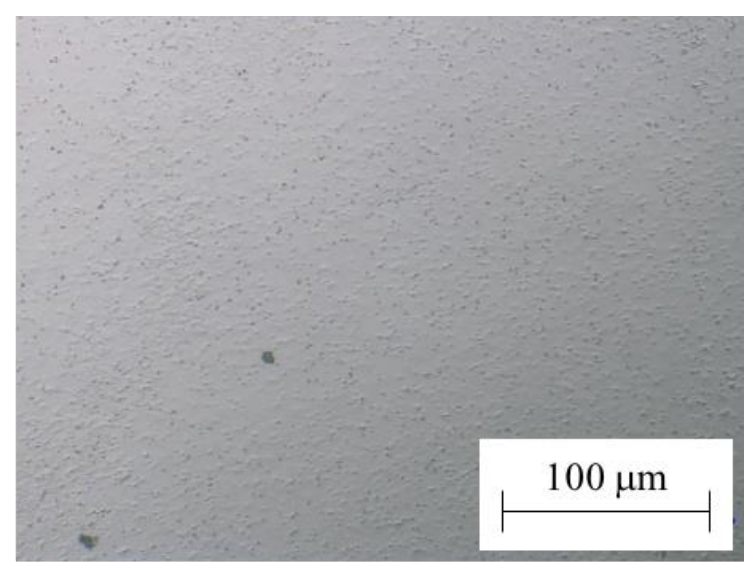

(b)

Fig. 2. (Color Online) 
Fig. 3
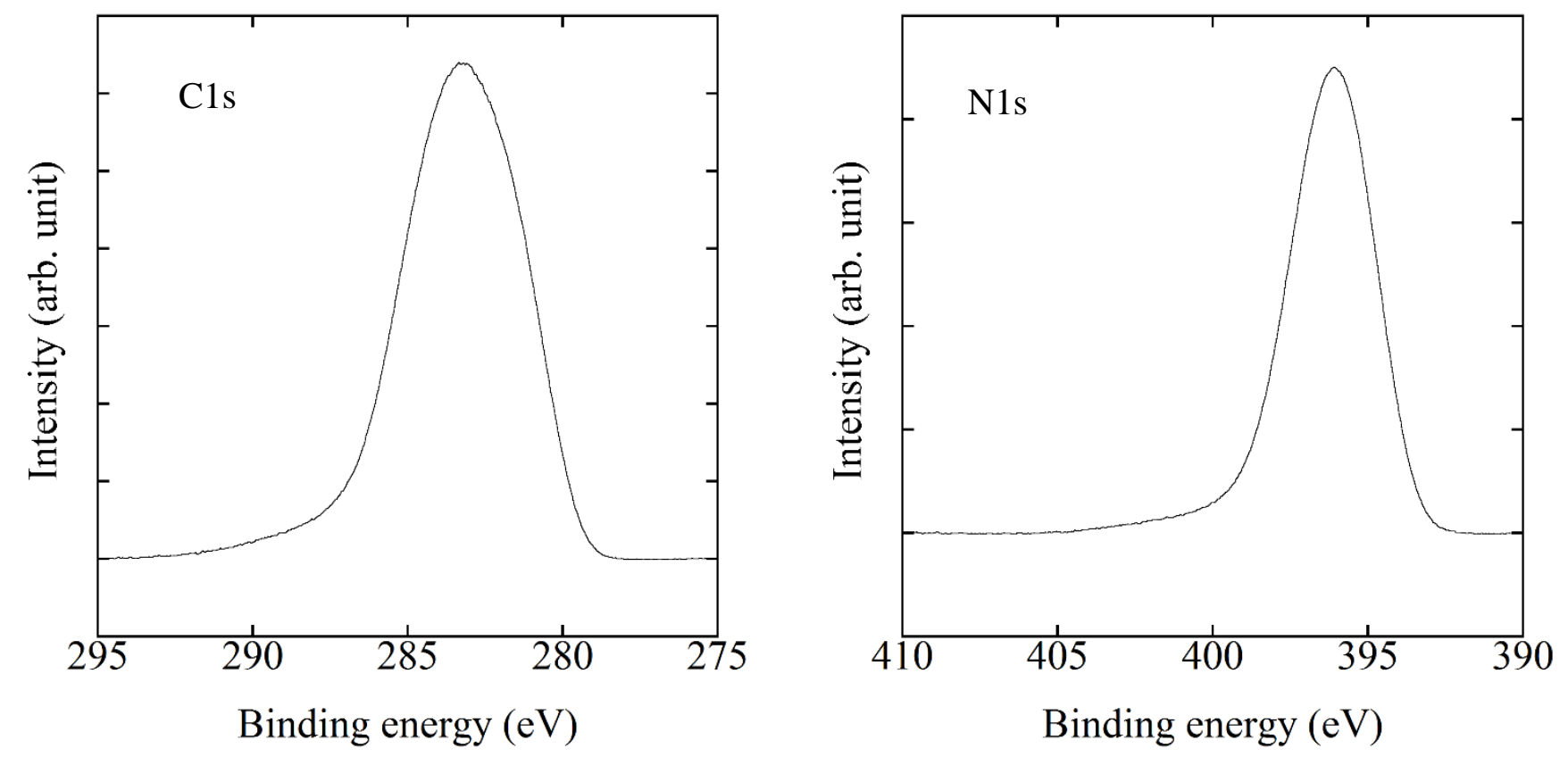


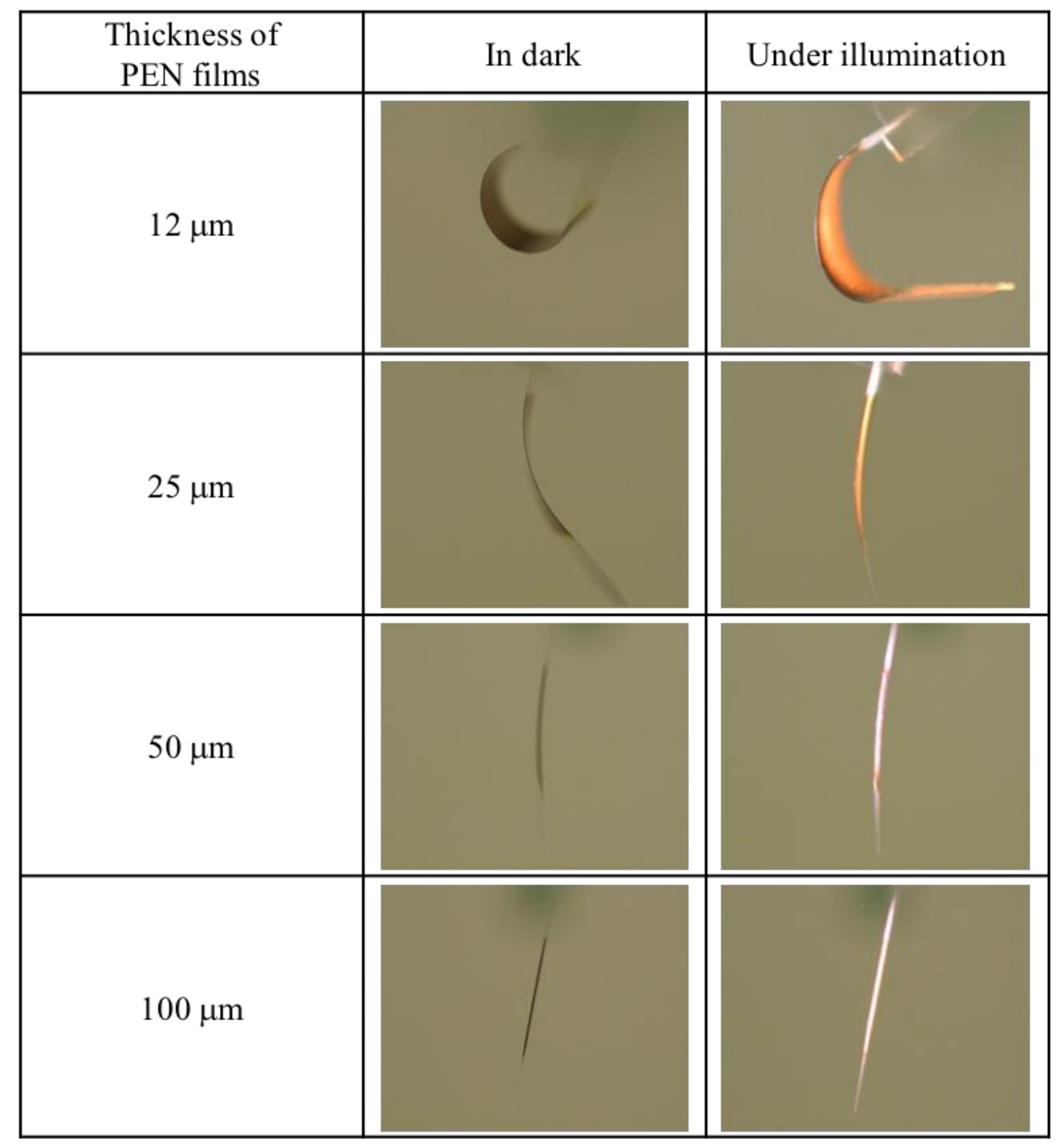

Fig. 4 (Color Online) 


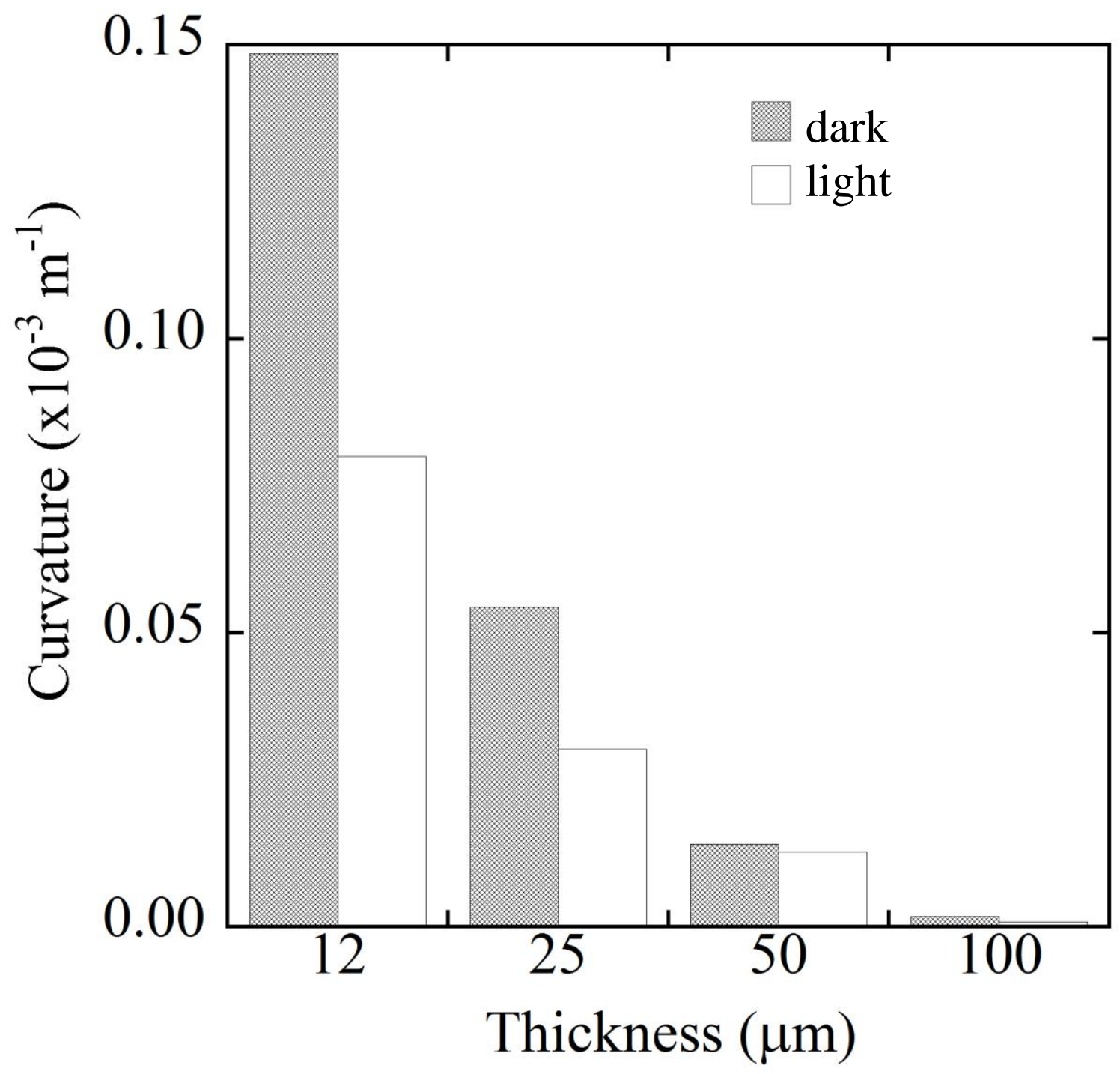

Fig. 5 


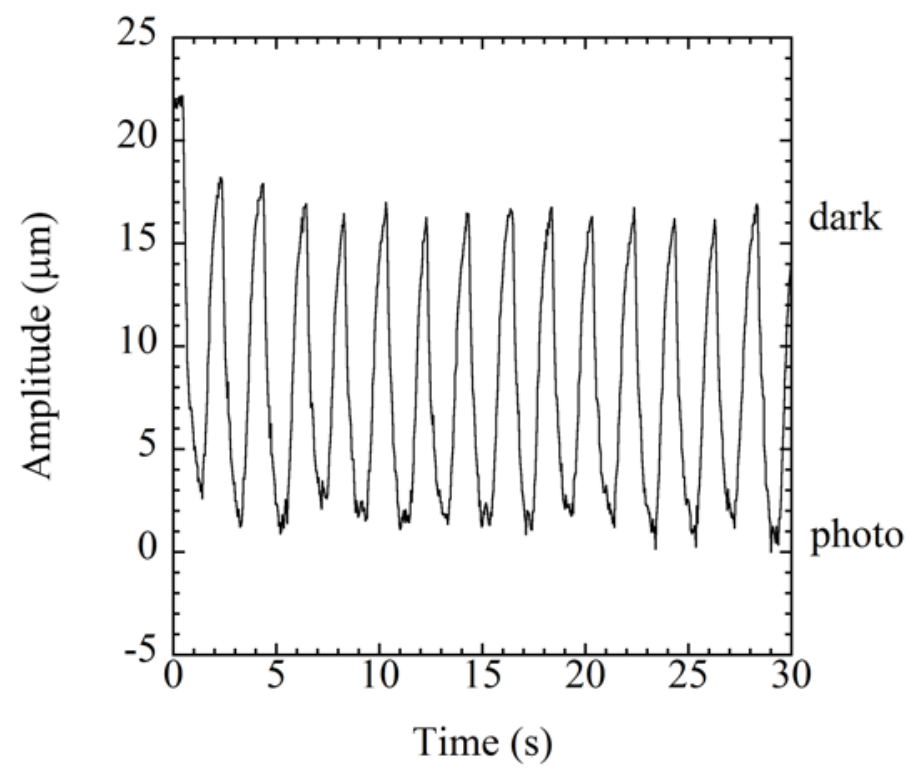

(a)

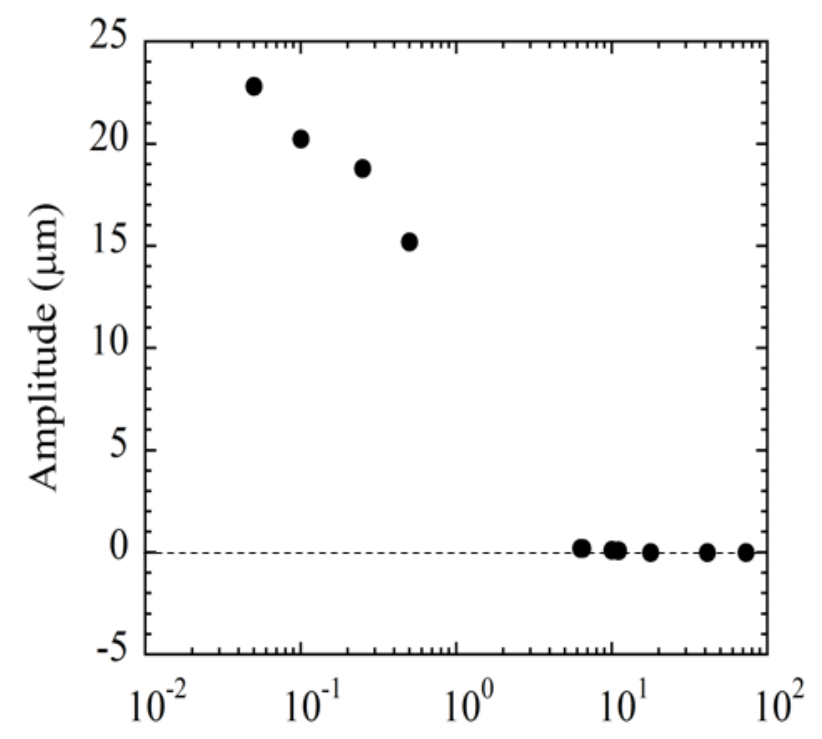

Chopping frequency $(\mathrm{Hz})$

(b)

Fig.6 


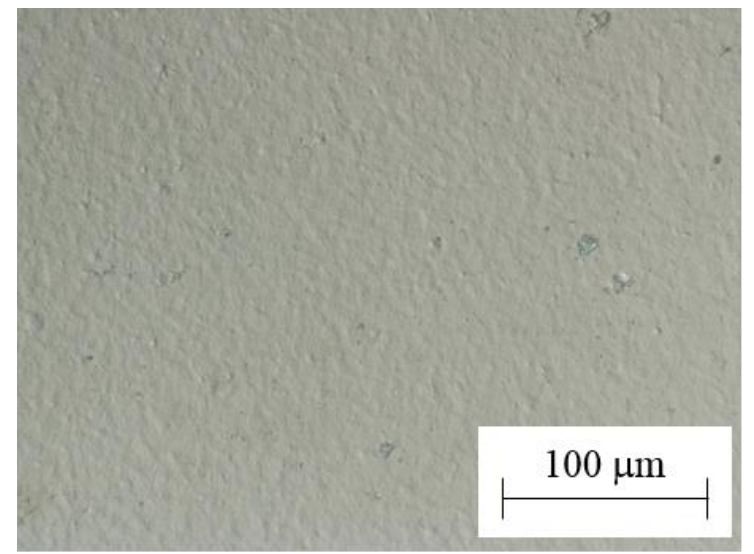

(a)

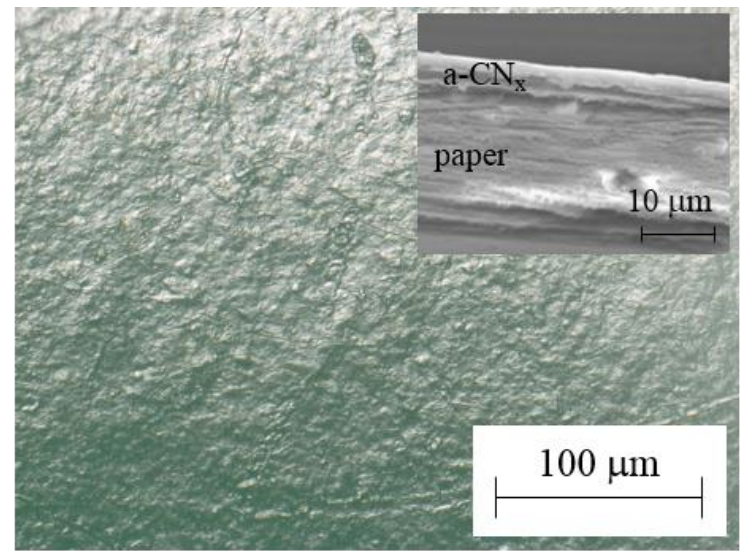

(b)

Fig. 7 (Color Online) 

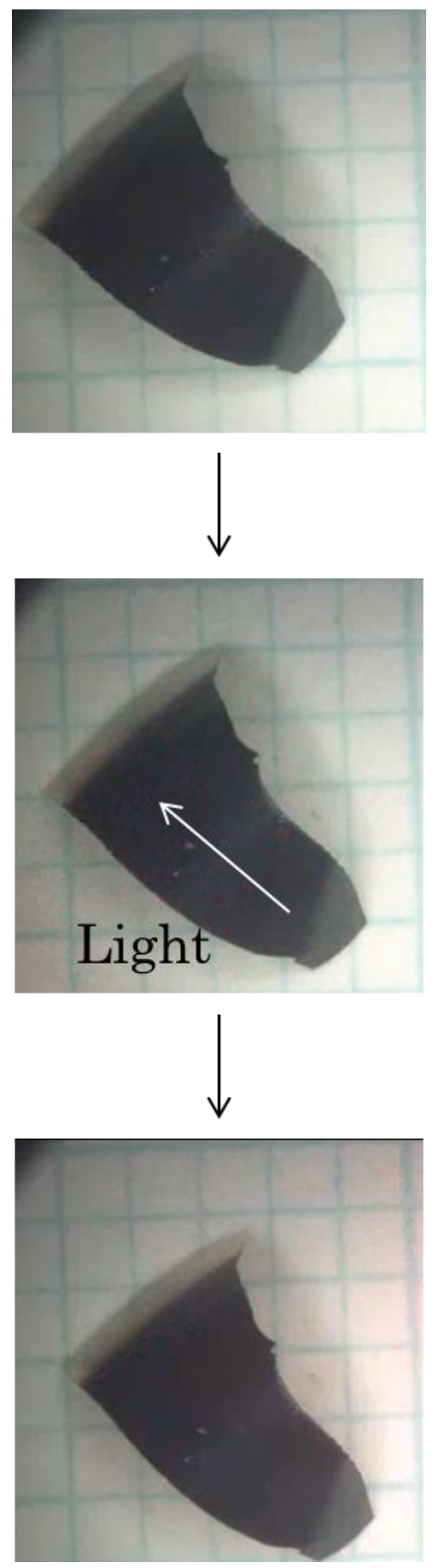

Fig. 8 (Color Online) 